\title{
Structural changes in the US economy: is there a role for monetary policy? ${ }^{*}$
}

\author{
Fabio Canova \\ U-Bern, ICREA-UPF and CEPR \\ Luca Gambetti \\ Universitat Autonoma de Barcelona and RECent
}

This Draft: April 2008

\begin{abstract}
This paper investigates the contribution of monetary policy to the changes in output growth and inflation dynamics in the US. We identify a policy shock and a policy rule in a time-varying coefficients VAR using robust sign restrictions. The transmission of policy shocks has been relatively stable. The variance of the policy shock has decreased over time, but policy shocks account for a small fraction of the level and of the variations in inflation and output growth volatility and persistence. We find little evidence of a significant increase in the long run response of the interest rate to inflation. A more aggressive inflation policy in the 1970s would have produced large output growth costs.

Key words: Monetary policy, Inflation persistence, Transmission of shocks, Time varying coefficients structural VARs

JEL Classification numbers: E52, E47, C53

\footnotetext{
${ }^{*}$ We would like to thank two anonymous referee, Jim Bullard, Tim Cogley, Tom Sargent and the partici-
} pants of many conferences and seminars for comments and suggestions. An earlier version of this paper has circulated with the title "Structural changes in the US economy: bad policy or bad luck". Both authors acknowledge the financial support of the Spanish Ministry of Education through the grant SEJ-2004-21682-E. Canova also acknowledges financial support from CREI.
\end{abstract}




\section{Introduction}

There is considerable evidence suggesting that the US economy has fundamentally changed over the last three decades. In particular, several authors have noted a marked decline in the volatility of real activity and in the volatility and persistence of inflation since the early 1980s (see e.g. Blanchard and Simon (2000), McConnell and Perez Quiros (2000), and Stock and Watson (2003)). What are the reasons behind such a decline? A stream of literature attributes these changes to alterations in the mechanisms through which exogenous shocks spread across sectors and propagate over time. Since the transmission mechanism depends on the structure of the economy, such a viewpoint implies that important characteristics, such as the behavior of consumers and firms or the preferences of policymakers, have changed over time. The literature has paid particular attention to monetary policy. Several studies, including Clarida, Gali and Gertler (2000), Cogley and Sargent (2001, 2005), Lubik and Schorfheide (2004), have argued that monetary policy was "loose" in fighting inflation in the 1970s but became more aggressive since the early 1980s and see in this change of attitude the reason for the observed changes in inflation and real activity. This view, however, is far from unanimous. For example, Bernanke and Mihov (1998), Leeper and Zha (2003), Orphanides (2004), Hanson (2006) suggest that the same policy rule prevailed over the last 30 years, while Sims and Zha (2006) indicate that changes in the variance of exogenous shocks may be responsible for the fall in volatility and persistence. McConnell and Perez Quiros (2000), Campbell and Herkovitz (2006), on the other hand, point out that alterations in the parameters of the private sector can account for the observed changes.

This controversy is not new. In the past rational expectations econometricians (e.g. Sargent (1984)) have argued that policy changes involving regime switches dramatically alter private agent decisions and, as a consequence, the dynamics of the macroeconomic variables, and searched for historical episodes supporting this view (see e.g. Sargent (1999)). VAR econometricians, on the other hand, often denied the empirical relevance of this argument suggesting that the systematic portion of monetary policy has rarely been altered and that policy changes are better characterized as random variations for the non-systematic part (Sims, (1982)). This long standing debate has now been cast into the framework of "bad policy" (failure to adequately respond to inflationary pressures), or "bad luck" (shocks are drawn from a distribution with time varying moments), and new evidence has been collected thanks to the development of empirical methods which allow for time variations in the structure of the economy and in the variance of the exogenous processes. Overall, 
the role that monetary policy had in shaping the observed changes in the US is still open.

This paper provides new evidence on this issue, by estimating a structural time varying coefficient model with stochastic volatility and identifying monetary policy using robust sign restrictions. We innovate upon the literature in three important aspects. Relative to Cogley and Sargent (2005), we take a structural rather than a reduced form approach, while relative to Primiceri (2005), who use a-theoretical Choleski scheme, we identify monetary policy shocks using restrictions consistent with a large class of currently used DSGE models. Relative to Stock and Watson (2003), and Biovin and Giannoni (2006), we propose a method to trace out the effects of changes in the parameters of the policy rule, which builds on the work of Gallant et. al. (1996) and Koop et. al. (1996). Finally, rather than associating the timing of the changes in monetary policy with variations in output growth and inflation dynamics, we quantify the contribution of the systematic and non-systematic part of monetary policy to the observed variations.

We work with sign restrictions in the identification process for two reasons. The contemporaneous zero restrictions conventionally used are often absent in those theoretical models one employs to guide the interpretation of the results. In addition, while the restrictions we employ are robust to the parameterization, common to both flexible and sticky price models (see e.g. Gambetti et. al., 2005), and independent of whether the economic environment delivers determinate or indeterminate solutions (see e.g. Lubik and Schorfheide, 2004), those imposed by more standard approaches leave the system underidentified if indeterminacies are present. Our methodology to conduct counterfactuals is preferable because the conditional covariance structure implied by the structural model is used to trace out the effect of different policy scenarios. Hence, changes in policy parameters may trigger changes in the parameters of the private sector, if the two set of parameters are correlated.

We show that the transmission of policy shocks has been relatively stable over time and detect significant changes - which make monetary shocks more powerful in affecting inflation and real activity - only in the latter part of the sample. As in Sims and Zha (2006), we find posterior evidence of a considerable decrease in the variance of the policy shock. However, we document that policy shocks explain a small fraction of the average variability and persistence of output growth and inflation and that the decline in inflation variability comes from sources other than the monetary policy shocks. Our posterior analysis does not support the idea that monetary policy has become significantly more aggressive in fighting inflation since the early 1980s, nor do we find overwhelming evidence that a weak response of interest rates to inflation is sufficient to explain the 1970s. However, we do find that the 
posterior median of the long run inflation coefficient in the policy equation was low in the 1970s, and that increased after Volker was appointed chairman of the Fed. Finally, we show that a more aggressive inflation policy would have reduced the level and the persistence of inflation, but the real costs would have been substantial.

Overall, while the crudest version of the "bad policy" hypothesis has low posterior support, the evidence we uncovered is consistent both with more sophisticated versions of this proposition (see Schorfheide (2005)), as well as with alternative hypotheses suggested in the literature. To disentangle the various possibilities, a model in which preferences, technologies and the distributions of the shocks are allowed to change along with the preferences of the Fed is needed. While such a model is still too complex to be estimated (see e.g. Rubio Ramirez and Fernandez Villaverde (2007)), approximations of the type employed in Canova (2005), can shed important light on this issue.

The rest of the paper is organized as follows. Section 2 presents the empirical model, section 3 the estimation procedure, section 4 the results and section 5 the conclusions.

\section{The empirical model}

Let $y_{t}$ be a vector including a short term interest rate, the inflation rate, output growth and M2 growth in that order. We assume that $y_{t}$ admits the representation:

$$
y_{t}=A_{0, t}+A_{1, t} y_{t-1}+\ldots+A_{p, t} y_{t-p}+\varepsilon_{t}
$$

where $A_{0, t}$ contains time-varying intercepts, $A_{i, t}$ are matrices of time-varying coefficients, $i=1, \ldots, p$ and $\varepsilon_{t}$ is a Gaussian white noise with zero mean and time-varying covariance matrix $\Sigma_{t}$. Let $A_{t}=\left[A_{0, t}, A_{1, t} \ldots, A_{p, t}\right]$, and $\theta_{t}=\operatorname{vec}\left(A_{t}^{\prime}\right)$, where $\operatorname{vec}(\cdot)$ is the column stacking operator. We assume that all the roots of the VAR polynomial lie outside the unit circle at every $t$ - this is sufficient to make $y_{t}$ locally stationary. Given this condition, we postulate the following law of motion for $\theta_{t}$ :

$$
\theta_{t}=\theta_{t-1}+\omega_{t}
$$

where $\omega_{t}$ is a Gaussian white noise with zero mean and covariance $\Omega$. We let $\Sigma_{t}=F_{t} D_{t} F_{t}^{\prime}$, where $F_{t}$ is lower triangular, with ones on the main diagonal, and $D_{t}$ a diagonal matrix. Let $\sigma_{t}$ be the vector of the diagonal elements of $D_{t}^{1 / 2}$ and $\phi_{i, t}, i=1, \ldots, n-1$ the column vector formed by the non-zero and non-one elements of the $(i+1)$-th row of $F_{t}^{-1}$. We assume:

$$
\begin{aligned}
\log \sigma_{t} & =\log \sigma_{t-1}+\xi_{t} \\
\phi_{i, t} & =\phi_{i, t-1}+\psi_{i, t}
\end{aligned}
$$


where $\xi_{t}$ and $\psi_{i, t}$ are Gaussian white noises with zero mean and diagonal covariance matrix $\Xi$ and $\Psi_{i}$, respectively. We also assume that $\psi_{i, t}$ is independent of $\psi_{j, t}, j \neq i$, and let $\phi_{t}=\left[\phi_{1, t}^{\prime}, \ldots, \phi_{n-1, t}^{\prime}\right], \psi_{t}=\left[\psi_{1, t}^{\prime}, \ldots, \psi_{n-1, t}^{\prime}\right]$, and $\Psi$ be the covariance matrix of $\psi_{t}$. Finally, we assume $\xi_{t}, \psi_{t}, \omega_{t}, \varepsilon_{t}$ are mutually uncorrelated at all leads and lags. In principle, one could make $\varepsilon_{t}$ and $\omega_{t}$ correlated. However, it is well known that such a model can be equivalently represented with a setup where shocks are mutually uncorrelated but $\varepsilon_{t}$ is serially correlated. Since our measurement equation is a VAR, such a flexibility is unneeded here. Note that the specification in (3) and (4) is similar to the one employed by Primiceri (2005). Relative to Cogley and Sargent (2005), it allows $\psi_{t} \neq 0$ at each $t$.

The dynamic of $y_{t}$ can be studied using the instantaneous (local) MA representation

$$
y_{t}=\mu_{t}+\sum_{k=1}^{\infty} C_{k, t} \varepsilon_{t-k}
$$

where $C_{0, t}=I, \mu_{t}=\sum_{k=0}^{\infty} C_{k, t} A_{0 t}, C_{k, t}=\mathcal{S}_{n, n}\left(\mathbf{A}_{t}^{k}\right), \mathbf{A}_{t}=\left(\begin{array}{c}A_{t} \\ I_{n(p-1)} 0_{n(p-1), n}\end{array}\right)$ and $\mathcal{S}_{n, n}(X)$ is a function selecting the first $n$ rows and $n$ columns of the matrix $X$. Our analysis will focus on the variability and the persistence of inflation and output growth and on the contribution of monetary shocks to these statistics. The variance of $y_{i t}$ is given by the $i$-th diagonal element of $V_{t}\left(y_{t}\right)$, i.e. $V_{t, i, i}\left(y_{t}\right)=\left(\sum_{k=0}^{\infty} C_{k, t} \Sigma_{t} C_{k, t}^{\prime}\right)_{i, i}$. We measure persistence as the $i$-th element of the spectral density matrix at frequency zero, normalized by the variance of the series, that is, we use $P_{t, i, i}\left(y_{t}\right)=\frac{f_{t, i, i}\left(y_{t}, 0\right)}{V_{t, i, i}\left(y_{t}\right)}$, where $f_{t}\left(y_{t}, 0\right)=\frac{\left(\sum_{k=0}^{\infty} C_{k, t}\right) \Sigma_{t}\left(\sum_{k=0}^{\infty} C_{k, t}\right)^{\prime}}{2 \pi}$.

\subsection{Characterizing Monetary Policy}

We are interested in three features of monetary policy: the transmission of policy shocks; their variance and the parameters of the policy rule.

\subsubsection{Identifying monetary policy}

To identify a policy shock we impose three restrictions: a policy shock (i) is orthogonal to all other shocks; (ii) it increases the interest rate for two periods; (iii) it reduces output growth, inflation and money growth for two periods. To obtain shocks with these characteristics we let $G_{t}$ be the unique lower triangular matrix such that $G_{t} G_{t}^{\prime}=\Sigma_{t}$, and let $h_{t}$ be a unit vector, uniformly distributed over the unit-sphere, satisfying (ii)-(iii). Responses to the policy shock are $I R_{y}(t, k)=C_{k, t} G_{t} h_{t}$ and the proportion of variance and persistence of $y_{i t}$ explained by the policy shock are $\frac{V_{t, i}^{m p}\left(y_{t}\right)}{V_{t, i, i}\left(y_{t}\right)}$ and $\frac{P_{t, i}^{m p}\left(y_{t}\right)}{P_{t, i, i}\left(y_{t}\right)}$ respectively, where $V_{t, i}^{m p}\left(y_{t}\right)=\sum_{k=0}^{\infty}\left(C_{k, t} G_{t} h_{t}\right)_{i}^{2}$, $P_{t, i}^{m p}\left(y_{t}\right)=\frac{\left(\sum_{k=0}^{\infty} C_{k, t} G_{t} h_{t}\right)_{i}^{2}}{2 \pi V_{t, i, i}\left(y_{t}\right)}$ and $\left(\sum_{k=0}^{\infty} C_{k, t} G_{t} h_{t}\right)_{i}^{2}$ is the contribution of the policy shock to the spectral density of $y_{i t}$ at frequency zero. 
We choose to work with sign restrictions to identify shocks for two reasons. First, the contemporaneous zero restrictions conventionally used are often absent in those theoretical (DSGE) models economists like to use to guide the interpretation of VAR results. Second, a set zero restrictions, which satisfies the standard order condition for identification, does not deliver an identified system in the case of indeterminacy (in this case, there are at least $n+1$ shocks). As shown by Lubik and Schorfheide (2004), a small scale version of the model used in Gambetti et. al (2005), delivers the same qualitative implications we use as identifying, both in determinate and in indeterminate scenarios.

Canova and Paustian (2007) showed that sign restrictions work well in recovering the features of the DGP if the shock one wants to identify has large variance or if restrictions are abundant. Since monetary shocks are typically considered a minor source of contemporaneous output growth and inflation fluctuations, one must insure that enough restrictions are imposed to make the analysis meaningful. We have experimented identifying just the monetary shock and imposing restrictions at various horizons, and jointly identifying a monetary, a real demand and a supply shock using only contemporaneous restrictions. The results we present are robust to these variations. Hence, the signal that policy shocks produce appears to be strong enough to allow sign restrictions to properly work.

To obtain the parameters of the policy rule, we assume that the interest rate equation contains a systematic component, given by the response of the interest rate to its own lags and the lags and contemporaneous values of inflation, output growth and money growth; and a non-systematic component, the policy shock. By inverting $G_{t} H_{t}$, where $H_{t}$ is an orthonormal matrix whose first column is $h_{t}$, the first equation of the structural VAR is

$$
h_{t}^{\prime} G_{t}^{-1} y_{t}=h_{t}^{\prime} G_{t}^{-1} A_{0, t}+h_{t}^{\prime} G_{t}^{-1} A_{1, t} y_{t-1}+\ldots+h_{t}^{\prime} G_{t}^{-1} A_{p, t} y_{t-p}+e_{1, t}
$$

In (6) $e_{1, t}$ is an orthogonal white noise with unit variance, $\gamma_{0, t}=h_{t}^{\prime} G_{t}^{-1}$, and $\gamma_{1, t}=$ $\left[h_{t}^{\prime} G_{t}^{-1} A_{0, t}, h_{t}^{\prime} G_{t}^{-1} A_{1, t}, \ldots, h_{t}^{\prime} G_{t}^{-1} A_{p, t}\right]^{\prime}$ contains the structural parameters on contemporaneous and lagged variables.

To calculate the variance of the policy shock, we normalize the contemporaneous interest

rate coefficient to one. This implies that the policy shock is $e_{t}^{m p}=\frac{1}{h_{t}^{\prime} g_{t}} e_{1, t}$ and its variance is $\left(1 / h_{t}^{\prime} g_{t}\right)^{2}$, where $g_{t}$ is the first column of $G_{t}$.

\subsection{Policy counterfactuals}

Evaluating the effects of hypothetical actions is important to understand to what extent monetary policy is responsible for the observed changes. However, such an exercise is far 
from trivial and most of the counterfactuals present in the literature are poorly designed. To understand why consider the following example. Suppose we want to evaluate whether changing the policy rule prevailing in period $j$ changes $X$, a vector of statistics of $y_{t}$ (i.e. variances, correlations, etc.). To perform such an exercise one typically draws the coefficients of the policy rule from the distribution obtained in period $j^{\prime} \neq j$ and all the other coefficients from the distribution obtained in period $j$, generates data, computes $X$ and compares it with the actual one. Such an approach is incorrect since the coefficients of the reduced form are correlated ( $\Omega$ is, in general, a full matrix). Therefore, when policy coefficients vary, structural coefficients in the other equations will vary as well. This correlation structure is disregarded when standard counterfactuals are performed. Furthermore, if the draws for the policy coefficients in period $j^{\prime}$ are improbable or implausible from the point of view of the distribution of these coefficients in period $j$, the outcomes of the experiment are unreliable. The method we propose avoids these problems. While we exclusively focus on the parameters of the policy rule, the methodology is general and can be employed to study variations in any set of structural parameters of interest.

Structural VAR parameters can be written as linear combinations of the reduced form parameters, i.e. $\gamma_{t}=\left(J_{t}^{-1} \otimes I_{n p+1}\right) \theta_{t}$, where $J_{t}^{-1}=H_{t}^{\prime} G_{t}^{-1}$ and $I_{n p+1}$ is a $n p+1$ identity matrix. Consequently, they evolve according to

$$
\gamma_{t}=\left(J_{t}^{-1} \otimes I_{n p+1}\right)\left(J_{t-1}^{-1} \otimes I_{n p+1}\right)^{-1} \gamma_{t-1}+\eta_{t}
$$

where $\eta_{t}=\left(J_{t}^{-1} \otimes I_{n p+1}\right) \omega_{t}$ is the vector of shocks to structural parameters. Let $\tilde{\eta}_{t}=$ $\tilde{J}_{t} \omega_{t}$ be a subvector of $\eta_{t}$ containing the shocks of interest and $\tilde{J}_{t}$ a matrix formed by the appropriate rows of $\left(J_{t}^{-1} \otimes I_{n p+1}\right)$. To trace out the effects $\tilde{\eta}_{t}$, one can use a version of the generalized impulse response approach of Gallant et. al. (1996) and Koop et. al. (1996). Assume that information on $y_{t-1}, \theta_{t-1}, \Omega$ and $\tilde{J}_{t}$ is available. The dynamic effect at $t+k$, $k=0,1,2, \ldots$, produced by a shock $\tilde{\eta}_{t}$ of size $\delta$ can be obtained as the difference between two conditional expectations of $y_{t+k}$ a

$$
G I R_{y}(t, k)=E\left(y_{t+k} \mid y_{t-1}, \theta_{t-1}, \tilde{J}_{t}, \Omega, \tilde{\eta}_{t}=\delta\right)-E\left(y_{t+k} \mid y_{t-1}, \theta_{t-1}, \tilde{J}_{t}, \Omega\right) \quad k=1,2, \ldots
$$

The way we have setup these conditional expectations implies that the shock could be reversed in the future. We chose this option because results are more stable and because the chance of drawing an explosive path is smaller. To make the shock permanent it is sufficient to modify the information set of the first conditional expectation setting all future shocks to the coefficients to zero, i.e. the first conditional expectation is $E\left(y_{t+k} \mid y_{t-1}, \theta_{t-1}, \tilde{J}_{t}, \Omega, \tilde{\eta}_{t}=\right.$ 
$\left.\delta, \tilde{\eta}_{t+1}^{t+k}=0\right)$.

In this paper, we are interested in performing the following experiment: what would happen to inflation and output growth dynamics if monetary policy were more aggressive in fighting inflation - where "more aggressive" means that the long run inflation coefficient in the policy rule is larger. To undertake such an experiment we assume that $\tilde{\eta}_{t}$ includes the shocks to the coefficients of lagged inflation and lagged interest rate of the monetary policy rule and set $\delta$ equal to the posterior standard error for shocks to the coefficients of lagged inflation and zeros for shocks to the coefficients of the lagged interest rate. Since this ensures that the long run response to inflation increases, our design allows us to claim that monetary policy was uniformly tighter in the experiment. Furthermore, our choice of $\delta$ implies that the change was "typical", in the sense of Leeper and Zha (2003) relative to the sample.

\section{Estimation}

The TVC-VAR model is estimated using Bayesian methods. We use quarterly data in the exercise: data from 1959:1 up 1967:1 is used to calibrate the priors and data from 1967:2 to 2006:4 to estimate the model. Letting $\hat{x}$ denote the OLS estimate of parameter $x$, the prior densities are $p\left(\theta_{0}\right)=N\left(\hat{\theta}, \hat{V}_{\theta}\right), p\left(\phi_{0}\right)=N\left(\hat{\phi}, \hat{V}_{\phi}\right), p\left(\log \sigma_{0}\right)=N\left(\log \hat{\sigma}, I_{n}\right) p(\Omega)=$ $I W\left(0.0005 \times(\operatorname{dim}(\theta)+1) \times \hat{V}_{\theta},(\operatorname{dim}(\theta)+1)\right), p(\Xi)=I W\left(0.001 \times 5 \times I_{n}, 5\right), P\left(\Psi_{i}\right)=$ $I W\left(0.001 \times(i+1) \times \hat{V}_{\phi}, i+1\right)$. We set $\mathrm{p}=2$. For each year in the estimation sample, we identify the monetary policy shock. This means that we collect 40 impulse response functions, one for each of year in the sample. The data is from the FRED data base of the Federal Reserve Bank of San Louis. For the short term interest rate we use the federal funds rate (FEDFUNDS), for inflation the growth rate of the GDP deflator (GDPDEF), for output growth the growth rate of real GDP (GDPC1) and for money growth the growth rate of M2 (M2SL). The mnemonic used by FRED are in parenthesis.

Posterior distributions for the structural parameters are not available in a closed form. MCMC methods are used to draw from the posteriors. Estimation of reduced form TVCVAR models is rather standard: it requires treating time varying parameters (coefficients, covariations and volatilities) as separate blocks in a Gibbs sampler algorithm. The particular implementation we use follows Primiceri (2005). Let $x$ be a $(q \times 1)$ vector, and let $x^{T}$ be the sequence $\left[x_{1}^{\prime}, \ldots, x_{T}^{\prime}\right]^{\prime}$. Each cycle of the Gibbs sampler requires sampling from the conditional distributions of $\left(\sigma^{T}, s^{T}, \phi^{T}, \theta^{T}, \Omega, \Xi, \Psi\right)$, where $s^{T}$ is an indicator function defined 
in the appendix. Details on how to sample from these distributions are in the appendix.

Given draws for the parameters, sequences for the unobservable states of the model can be obtained by running first the Kalman filter through the sample. Then, given the conditional mean and variance of the terminal state, the mean and the variance of the states at $t \in[T-1,1]$ are obtained using standard backward Kalman recursions.

Under regularity conditions and after a burn-in period, iterations on these steps produce draws from the joint posterior density of the parameters. 100000 iterations are performed. CUMSUM graphs are used to check for convergence and the chain appears to have converged, roughly, after 5000-6000 draws. The densities for the parameters are typically well behaved. We discard the first 50000 and keep one every 5 of the remaining 50000 draws to break the autocorrelations of the draws and discard all the draws generating non-converging responses. Once draws from the posterior distributions of the reduced form parameters are obtained, structural analysis is performed applying the identification filter and keeping the draws satisfying the restrictions.

As mentioned our model features two shocks: shocks to the variables of the VAR and shocks to the coefficients of the model. Computing responses to monetary policy shocks is rather standard. The next algorithm summarizes the steps needed.

1. Draw $\theta_{t}$ and $\Sigma_{t}$, compute the lower triangular matrix $G_{t}$ such that $G_{t} G_{t}^{\prime}=\Sigma_{t}$.

2. Draw $w_{t}$ from a $n$-variate standard normal and set $h_{t}=w_{t} /\left\|w_{t}\right\|$.

3. Compute $C_{j, t} G_{t} h_{t}$ for $j=0, \ldots, J$, where $J$ is the number of periods for which sign restrictions have to be satisfied.

4. If the restrictions hold, store the responses.

5. Repeat 1-4, until M draws are found.

To compute responses to shocks to the coefficients of the policy rule for horizon $k=$ $1, \ldots, K$, let $\mathbf{y}_{t}=\left[y_{t}^{\prime}, 0_{(n-1) p}\right]^{\prime}, \mathbf{A}_{0 t}=\left[A_{0 t}^{\prime}, 0_{(n-1) p}\right]^{\prime}$. and proceed as follows:

1. Draw $\theta_{t-1}$ and $\Omega$. Draw $\left\{\omega_{t}^{t+K}\right\}$ from a $N(0, \Omega)$, compute $\left\{\theta_{t}^{t+K}\right\}$ and construct the sequences of companion matrices $\left\{\mathbf{A}_{t}^{t+K}\right\}$ of the system.

2. Iterate on $\mathbf{y}_{t}=\mathbf{A}_{0, t}+\mathbf{A}_{t} \mathbf{y}_{t-1}$ for $K$ periods. Since $\omega_{t}$ and $\varepsilon_{t}$ are independent, $\varepsilon_{t}$ does not enter the computations. Save the first $n$ elements of $\mathbf{y}_{t}^{t+K}$, i.e. $y_{t}^{t+K}$. 
3. Repeat steps 1-2 L times and take $\frac{1}{L} \sum_{\ell=1}^{L} y_{t}^{t+k, \ell}$ as a realization of $E\left(y_{t+k} \mid y_{t-1}, \theta_{t-1}, \tilde{J}_{t}, \Omega\right)$, $k=1, \ldots, K$.

4. Repeat steps 1-3 M times.

5. Draw $\theta_{t-1}, \Omega$ and $\tilde{J}_{t}$ (available from the identification procedure). Draw $\omega_{t}$ conditional to $\tilde{\eta}_{t}$, from a Normal distribution with mean $\Omega \tilde{J}_{t}^{\prime}\left(\tilde{J}_{t} \Omega \tilde{J}_{t}^{\prime}\right)^{-1} \delta$ and variance $\Omega-\Omega \tilde{J}_{t}^{\prime}\left(\tilde{J}_{t} \Omega \tilde{J}_{t}^{\prime}\right)^{-1} \tilde{J}_{t} \Omega$ compute $\theta_{t}$ and construct $\mathbf{A}_{t}$. Draw $\left\{\omega_{t+1}^{t+K}\right\}$ from a $N(0, \Omega)$, compute $\left\{\theta_{t+1}^{t+K}\right\}$ and the implied $\left\{\mathbf{A}_{t+1}^{t+K}\right\}$.

6. Iterate on $\mathbf{y}_{t}=\mathbf{A}_{0, t}+\mathbf{A}_{t} \mathbf{y}_{t-1}, K$ periods; save the first $n$ elements of $\mathbf{y}_{t}^{t+K}$, i.e. $y_{t}^{t+K}$.

7. Repeat steps 5-6 L times and take $\frac{1}{L} \sum_{\ell=1}^{L} y_{t}^{t+k, \ell}$ as a realization of $E\left(y_{t+k} \mid y_{t-1}\right.$, $\left.\theta_{t-1}, \tilde{J}_{t}, \Omega, \tilde{\eta}_{t}=\delta\right), k=1, \ldots, K$.

8. Repeat steps 5-7 M times.

9. Take the difference between the $M$ stored values of $E\left(y_{t+k} \mid y_{t-1}, \theta_{t-1}, \tilde{J}_{t}, \Omega, \tilde{\eta}_{t}=\delta\right)$ and $E\left(y_{t+k} \mid y_{t-1}, \theta_{t-1}, \tilde{J}_{t}, \Omega\right)$, and compute the percentiles of interest.

The results we present below are obtained setting $\mathrm{M}=10000$ and $\mathrm{L}=50$.

\section{The Results}

We organize the presentation of the results around three general themes, which should shed some light on the contribution of monetary policy to the changes experienced in the US over the last 30 years: (i) Are there changes in the propagation and the variance of monetary policy disturbances? (ii) To what extent changes in the transmission and in the variability of monetary policy shocks explain the time profile of the variability and the persistence of output growth and inflation? (iii) Do the coefficients of the systematic part of the policy rule display significant variations? Would it have made a difference for macroeconomic performance if monetary policy had been more aggressive in fighting inflation?

Figure 1 presents the time profile of reduced form estimates of the posterior median (solid line) and of the highest 68 percent posterior interval (dotted lines) for the volatility (standard deviation) and persistence of inflation and output growth. Overall, the evidence confirms what we know from the literature (see e.g. Stock and Watson (2003) or Pivetta and Reis (2007)). The median of the posterior distribution of the two volatility measures has two peaks, one in 1974 and one in 1979, and it drops sharply at the beginning of the 
1980s. Since the 68 percent interval also shrinks at that time, there is posterior evidence that the so-called Great Moderation is indeed an important phenomenon. Consistent with the evidence of Cogley and Sargent (2005), the posterior median of inflation persistence falls at the beginning of the 1980s. Since the 68 percent posterior interval shrinks only in the late $1980 \mathrm{~s}$, persistence in the 1980s is a-posteriori indistinguishable from the one of the 1970s - here and in the next subsections, such a statement means that the posterior distribution of the difference between the estimates obtained at any date in the 1970s and 1980s always includes the zero line. The posterior median of output growth persistence is on average higher up to the early 80 than later and displays two peaks roughly synchronized with those in output growth volatility. Posterior uncertainty is however large making changes insignificant.

\subsection{Are there changes in the propagation of policy shocks?}

Figures $2 \mathrm{a}$ and $2 \mathrm{~b}$ present the time profile of the posterior median responses of inflation and output growth to identified policy shocks for horizons ranging from 1 to 12 quarters. The figures are constructed so that, in each year, the shock is of equal size. This allows us to isolate changes in the transmission mechanism from changes in the magnitude of the shocks over time. The shape of both output growth and inflation responses is similar over time. Inflation falls on impact and then reverts back to its pre-shock level after about one year. Output growth also falls on impact and the effect is slightly more persistent - it takes about 6 quarters to revert back to the pre-shock level.

Some quantitative differences in the median responses of both output growth and inflation are present but not around the end of the 1970s, as the literature suggests. What is clear instead is that, after an initial decline, the absolute value of the instantaneous responses of both output growth and inflation increases by 2 to 3 times in the 1990s and the responses in 1996 and 2006, the dates with the largest effects, are a-posteriori different from the responses of the 1980s. Since the response of the interest rate is practically unchanged over time, one must conclude that discretionary monetary policy has become more effective in influencing output growth and inflation in the later part of the sample. Figure 2c reports the time profile of the posterior distribution of the variance of output growth and inflation that would have resulted if policy shocks with constant variance would have been the only disturbances present in the economy ${ }^{1}$ (we plot the median and the highest 68 percent credible interval). Clearly, the pattern displayed in the figure is inconsistent with the

\footnotetext{
${ }^{1}$ This corresponds to the sum of squared impulse response functions.
} 
variance moderation experienced in the US: since the non-systematic component of policy has become more effective, output growth and inflation would have been more volatile in the 1990s-2000s than in the 1970s. Hence, the fall in the variance of output growth and inflation cannot come from changes in the transmission of policy shocks, and it must be generated by either a reduction of the variance of the policy shocks or by changes in the propagation of some non-policy shocks.

\subsection{Are there changes in the variance of policy shocks?}

Figure 3 displays the time profile of the median and the highest interval containing 68 percent of the posterior distribution of the standard deviation of the estimated policy shock. As in Sims and Zha (2006), we find that the median of the distribution is higher, on average, before 1985 than afterward. In addition, we find that posterior uncertainty falls up to 1998. Consequently, the volatility peak of 1980 is a-posteriori different from, say, the volatility present in the late 1990s. Interestingly, the volatility peak lags the volatility peak in inflation and output growth presented in figure 1 by one year and it is probably the result of Volker's choice of targeting monetary aggregates. Hence, the fall in these statistics may not have much to do with changes in the non-systematic component of policy.

\subsection{Inflation and output growth dynamics and policy shocks}

The previous two subsection have shown that the transmission of the policy shocks have very little to do with changes in the dynamics of inflation and output growth persistence and volatility. Furthermore, while the upward trend of the 1970s in the volatility of the policy shock is correlated with the upward trend in these statistics, the start of the Great Moderation predates the estimated fall in the volatility of the policy shocks.

To provide additional evidence on the role of monetary policy, we study whether the contribution of monetary policy shocks to the variability and persistence of inflation and output growth, which depends on both changes in the transmission of policy shock and in their variances, has changed in a manner with which consistent with giving monetary policy a causal role in the process. Cogley and Sargent $(2001,2005)$ found that there is synchronicity between changes in persistence and a narrative account of monetary policy changes. Since we perform a structural analysis, we can provide a quantitative assessment on the contribution of monetary policy shock to the observed changes.

Figure 4, which reports the time profile of the posterior median (solid line) and the posterior 68 percent interval (dotted lines) of contribution of the policy shock to the volatility 
and persistence of inflation and output growth, displays interesting features. The contribution of policy shocks is on average higher after 1985 for inflation volatility (18 percent vs. 12 percent), and on average lower after 1985 for output growth volatility (17 percent vs. 14 percent). The percentage of the persistence of inflation attributable to the monetary policy shock is roughly constant over time and low (about 10 percent), while the percentage of persistence of output growth accounted for by monetary policy shock almost doubles starting in 1990 (from 10 percent to more than 20 percent). Finally, and consistent with previous evidence, the posterior intervals around these median shares are large, making the changes a-posteriori insignificant.

In sum, the importance of the non-systematic component of monetary policy in shaping the time profile of inflation and output growth dynamics is limited. Our analysis fails to detect important changes in the transmission of policy shocks in the 1980s; we do find that changes in the variance of the policy shock are related to the swings in the time profile of inflation and output growth volatility and persistence in the 1970s but the level of these statistics explained by policy shocks is small and the "Great Moderation "phenomena predates the trend fall in the volatility of policy shocks. Furthermore, at least for inflation volatility, the contribution of monetary policy shocks has increased over time. Given that volatility has fallen, it must be the case that the contribution of shocks other than monetary policy has fallen dramatically since the 1980s.

\subsection{The evolution of the coefficients of the policy rule}

Characterizing the time profile of the systematic part of monetary policy is important because the response of the interest rate to economic conditions is part of the propagation mechanisms of all exogenous shocks. Hence, the systematic component of monetary policy could have influenced the dynamics of inflation and output growth even when policy shocks play a limited role.

Figure 5 presents the evolution of the posterior median (solid line) and the posterior 68 percent interval (dotted lines) for the three long run coefficients in the policy rule. The long run coefficient on inflation is the relevant measure to evaluate how policy has responded to inflation over time: the higher the value, the more aggressive has monetary policy been in that period. If a bad monetary policy is responsible for the pattern of high inflation and output growth volatility and persistence in the 1970's, we should detect a significant and permanent increase in the location of the posterior distribution at the beginning of 1980s.

The posterior median of the long run inflation coefficient is indeed low and often below 
one in the 1970s, and increases in 1981 to a level which is consistent with the conventional wisdom (about 1.8). However, it slowly declines up to 1997; it increases around the start of the millennium, and falls once more at the end of the sample. Since posterior uncertainty is large and tends to increase over time, the jump in the location of the distribution observed in 1981 is a-posteriori insignificant.

The time profile of variations in the posterior median of the output growth coefficients is also interesting. In particular, while policy looks countercyclical in the long run up to the beginning of the 1980s - the median value of the long run output growth coefficient is negative - it becomes procyclical after that. Since the beginning of 1980s, this coefficient has been generally small. While posterior uncertainty is quite large and this makes changes insignificant, one can notice a shift of the posterior mass from below zero in the 1970s to above zero since the early 1980s.

The evidence is therefore consistent with the idea that monetary policy was loose in the 1970s and turned more aggressive with Volker's appointment as chairman of the Fed but the change appears to be a-posteriori insignificant. The fact that inflation was lower and much more stable over the last ten years then in the 1970s indicates that we need a more complicated set of circumstances than a loose policy to produce the perverse outcomes of the 1970s. Hence, the crudest version of the "bad policy" hypothesis seems to be at odds with the data: there is no significant increase in the inflation coefficient of the policy rule nor overwhelming evidence that violation of the Taylor's principle is sufficient to explain the 1970s. The countercyclical nature of the long run output growth coefficient is consistent with the idea that the policy authority was mismeasuring output in the 1970s. However, the fact that this coefficient was negative even before the 1970s, casts doubts on explanations which rely on large mismeasurements of output to explain the increase in inflation volatility just after the first oil shock.

\subsection{What if monetary policy would have been more aggressive?}

It is common to argue, by mean of counterfactuals, that monetary policy failed in stabilizing inflation in the 1970s (see e.g. Clarida, Gali and Gertler (2000), Boivin and Giannoni (2006)) and that, had it followed a more aggressive stance, dramatic changes in the economic performance would have resulted. While exercises of this type are meaningful only in dynamic models with clearly stated microfundations, our structural setup allows us to approximate the ideal type of exercise without falling into the Lucas-critique type of traps, provided that the monetary policy equation we have identified is structural, and that the 
estimated correlation among coefficients is used in the experiment. The counterfactual we are interested in is the following: what would have happened if the policy response to inflation was significantly stronger, where by this we mean an increase in the long run value of the inflation coefficient? Since the model is non-linear, the quantitative outcomes of such an experiment depend on the size of $\delta$ and which coefficients entering the long run values are changed. Let $i=1,2, \ldots$ indicate the SVAR coefficients entering this long run measure. We set $\delta_{i}$ equal to the posterior standard deviation of the shock for all coefficients on lagged inflation and equal to zero for the coefficients of lagged interest rate.

We have computed responses for several values for $\delta$ and, while quantitatively the results change, the qualitative features we emphasize are unaltered. However, we should mention that increasing the size of the $\delta$ makes it more likely that the system ends up in an unstable region and this creates considerable computational problems.

Figures $6 \mathrm{a}$ and $6 \mathrm{~b}$ plot, respectively, the response of inflation and output growth to this shock. On the vertical axis we report percentage changes of output growth and inflation from their long run mean value in the years reported on the horizontal axis. A more aggressive stance would have had, as expected, important inflation effects: inflation falls at all dates we consider. The response of inflation to the shock is hump shaped, with the largest effect occurring after about ten-fifteen quarters. The fall is persistent and after about 10 years inflation would have been on average 0.1 percentage points lower. A tougher stance against inflation, however, would not have been painless. To reduce inflation by 1 percent one year after the shock, output growth should have fallen on impact by about 1.0-1.2 percent (1.2-4.0 percent after one year) and stay significantly below its long run value for 20 quarters.

Figure 7 shows the effects of a more aggressive inflation stance for inflation persistence. The solid line is the posterior median of inflation persistence computed using structural draws from the posterior distribution of $\theta_{t}$ and $\Sigma_{t}$ (we refer to this as unconditional persistence). The dotted line is the persistence evaluated at $E\left(\theta_{t} \mid \theta_{t-1}, \tilde{J}_{t}, \Omega_{t}, \tilde{\eta}_{t}=\delta\right.$ ) (we refer to this as conditional persistence). The difference between the two is the expected effect on inflation persistence of an increase in the inflation coefficients of the policy rule. The conditional persistence measure is systematically below the unconditional one. Hence, a more aggressive stance against inflation would have reduced inflation persistence. However, the difference between the two measures is small - less than 10 percent - and a-posteriori insignificant. Hence, a much larger shock would have been necessary to significantly reduce persistence making the output growth costs dramatic. 
In sum, while there was room for stabilizing inflation in the 1970 in terms of levels, such a stabilization would not have had major effects on inflation persistence and, given the large output growth costs, would have required considerable social consensus to be implemented.

\section{Conclusions}

This paper provides novel evidence on the contribution of monetary policy to the structural changes observed in the US economy over the last 30 years. From a methodological point of view we innovate in three respects: we provide (i) a sign scheme to identify monetary shocks in a TVC-VAR; (ii) a new method for conducting policy experiments; (iii) a quantitative assessment of the role of monetary policy in the Great Moderation episode.

There are several important facts that our investigation uncovers. We show that the transmission of policy shocks has been relatively stable over time and detect significant changes - which make monetary shocks more powerful in affecting inflation and real activity - only in the latter part of the sample. As in Sims and Zha (2006), we find posterior evidence of a considerable decrease in the variance of the policy shock. However, we document that policy shocks explain a small fraction of the average variability and persistence of output growth and inflation and that the decline in inflation variability comes from sources other than the monetary policy shocks. Our posterior analysis does not support the idea that monetary policy has become significantly more aggressive in fighting inflation since the early 1980s, nor do we find overwhelming evidence that a weak response of interest rates to inflation is sufficient to explain the 1970s. However, we do find that the posterior median of the long run inflation coefficient in the policy equation was low in the 1970s, and that increased after Volker was appointed chairman of the Fed. Finally, we show that a more aggressive inflation policy would have reduced the level and the persistence of inflation, but the output growth costs would have been substantial.

Since our results go against several preconceived notions present in the literature, it is important to highlight what features of our analysis may be responsible for the differences. First, our analysis uses a structural model while previous studies, which used the same level of econometric sophistication (such as Cogley and Sargent, 2001, 2005), have concentrated on reduced form estimates and used the timing of the observed changes to infer the contribution of monetary policy to changes in output growth and inflation. Our approach allows not only an informal evaluation but also to quantify a-posteriori the relationship between monetary policy, output and inflation dynamics. Second, relative to earlier studies such as 
Bernanke and Mihov (1998), Leeper and Zha (2003), or Hanson (2006), which use subsample analysis to characterize policy changes, we are able to precisely track the evolution of the coefficients over time and produce a more complete and reliable picture of the relatively minor variations present in the policy stance in the US.

Our results are in line with those obtained recursively estimating a small scale DSGE model with Bayesian methods (see Canova, 2005) and are somewhat in contrast with those of Boivin and Giannoni (2006), who use an indirect inference principle to estimate the parameters of a DSGE model over two subsamples. Apart from the fact that the counterfactuals they run are poorly designed, some of the differences could be due to the identification problems that their estimation approach faces for the model they consider (see Canova and Sala (2006) for details). Finally, our results are consistent with those of Sims and Zha (2006), despite the fact that, in that paper, variations in both the coefficients and the variance are accounted for with a Markov switching methodology. Relative to their work, our analysis emphasizes that factors other than monetary policy could be more important in explaining the structural changes in the US and provides a direct quantitative measure of the contribution of monetary policy to the "Great Moderation" episode.

Overall, while our analysis indicates that the crudest version of the "bad policy" hypothesis has low posterior support, the evidence we uncovered is consistent both with more sophisticated versions of this proposition (see Schorfheide (2005)) as well as with several alternative hypotheses present in the literature. In particular, the conjecture that there have been structural changes in the private sector behavior seems an interesting one. We plan to study this hypothesis in future work. 


\section{Appendix}

\section{Gibbs sampling algorithm}

- Step 1: sample from $p\left(\sigma^{T} \mid y^{T}, \theta^{T}, \phi^{T}, \Omega, \Xi, \Psi, s^{T}\right)$

To draw $\sigma^{T}$ we use the algorithm of Kim, Shephard and Chibb (KSC) (1998). Consider the system of equations $y_{t}^{*} \equiv F_{t}^{-1}\left(y_{t}-X_{t}^{\prime} \theta_{t}\right)=D_{t}^{1 / 2} u_{t}$, where $u_{t} \sim N(0, I), X_{t}=\left(I_{n} \otimes x_{t}^{\prime}\right)$, and $x_{t}=\left[1_{n}, y_{t-1} \ldots y_{t-p}\right]$. Conditional on $y^{T}, \theta^{T}$, and $\phi^{T}, y_{t}^{*}$ is observable. Squaring and taking the logarithm, we obtain

$$
\begin{gathered}
y_{t}^{* *}=2 r_{t}+v_{t} \\
r_{t}=r_{t-1}+\xi_{t}
\end{gathered}
$$

where $y_{i, t}^{* *}=\log \left(\left(y_{i, t}^{*}\right)^{2}+0.001\right)$ - KSC add the constant (0.001) to make estimation robust - $v_{i, t}=\log \left(u_{i, t}^{2}\right)$ and $r_{t}=\log \sigma_{i, t}$. Since, the innovation in (9) is distributed as $\log \chi^{2}(1)$, we use a mixture of 7 normal densities with component probabilities $q_{j}$, means $m_{j}-1.2704$, and variances $v_{j}^{2}(j=1, \ldots, 7)$ to transform the system in a Gaussian one, where $\left\{q_{j}, m_{j}, v_{j}^{2}\right\}$ are chosen to match the moments of the $\log \chi^{2}(1)$ distribution. The values are:

\begin{tabular}{cccc}
\hline \hline$j$ & $q_{j}$ & $m_{j}$ & $v_{j}^{2}$ \\
\hline \hline 1.0000 & 0.0073 & -10.1300 & 5.7960 \\
2.0000 & 0.1056 & -3.9728 & 2.6137 \\
3.0000 & 0.0000 & -8.5669 & 5.1795 \\
4.0000 & 0.0440 & 2.7779 & 0.1674 \\
5.0000 & 0.3400 & 0.6194 & 0.6401 \\
6.0000 & 0.2457 & 1.7952 & 0.3402 \\
7.0000 & 0.2575 & -1.0882 & 1.2626 \\
\hline \hline
\end{tabular}

Let $s^{T}=\left[s_{1}, \ldots, s_{T}\right]^{\prime}$ be a matrix of indicator variables selecting at each point in time the member of the mixture to be used for each element of $v_{t}$. Conditional on $s^{T},\left(v_{i, t} \mid s_{i, t}=\right.$ $j) \sim N\left(m_{j}-1.2704, v_{j}^{2}\right)$. Therefore we can use the algorithm of Carter and Kohn (1994) to draw $r_{t}(t=1, \ldots, \mathrm{T})$ from $N\left(r_{t \mid t+1}, R_{t \mid t+1}\right)$, where $r_{t \mid t+1}=E\left(r_{t} \mid r_{t+1}, y^{t}, \theta^{T}, \phi^{T}, \Omega, \Xi, \Psi, s^{T},\right)$ and $R_{t \mid t+1}=\operatorname{Var}\left(r_{t} \mid r_{t+1}, y^{t}, \theta^{T}, \phi^{T}, \Omega, \Xi, \Psi, s^{T}\right)$.

- Step 2: sample from $p\left(s^{T} \mid y^{T}, \theta^{T}, \sigma^{T}, \phi^{T}, \Omega, \Xi, \Psi\right)$

Conditional on $y_{i, t}^{* *}$ and $r^{T}$, we independently sample each $s_{i, t}$ from the discrete density defined by $\operatorname{Pr}\left(s_{i, t}=j \mid y_{i, t}^{* *}, r_{i, t}\right) \propto f_{N}\left(y_{i, t}^{* *} \mid 2 r_{i, t}+m_{j}-1.2704, v_{j}^{2}\right)$, where $f_{N}\left(y \mid \mu, \sigma^{2}\right)$ denotes a normal density with mean $\mu$ and variance $\sigma^{2}$. 
- Step 3: sample from $p\left(\phi^{T} \mid y^{T}, \theta^{T}, \sigma^{T}, \Omega, \Xi, \Psi, s^{T}\right)$

Consider again the system of equations $F_{t}^{-1}\left(y_{t}-X_{t}^{\prime} \theta_{t}\right)=F_{t}^{-1} \hat{y}_{t}=D_{t}^{1 / 2} u_{t}$. Conditional on $\theta^{T}, \hat{y}_{t}$ is observable. Since $F_{t}^{-1}$ is lower triangular with ones in the main diagonal, each equation in the above system can be written as

$$
\begin{aligned}
\hat{y}_{1, t} & =\sigma_{1, t} u_{1, t} \\
\hat{y}_{i, t} & =-\hat{y}_{[1, i-1], t} \phi_{i, t}+\sigma_{i, t} u_{i, t} \quad i=2, \ldots, n
\end{aligned}
$$

where $\sigma_{i, t}$ and $u_{i, t}$ are the $i$ th elements of $\sigma_{t}$ and $u_{t}$ respectively, $\hat{y}_{[1, i-1], t}=\left[\hat{y}_{1, t}, \ldots, \hat{y}_{i-1, t}\right]$. Under diagonality of $\Psi$, the algorithm of Carter and Kohn (1994) can be applied equation by equation, obtaining draws for $\phi_{i, t}$ from a $N\left(\phi_{i, t \mid t+1}, \Phi_{i, t \mid t+1}\right)$, where $\phi_{i, t \mid t+1}=$ $E\left(\phi_{i, t} \mid \phi_{i, t+1}, y^{t}, \theta^{T}, \sigma^{T}, \Omega, \Xi, \Psi\right)$ and $\Phi_{i, t \mid t+1}=\operatorname{Var}\left(\phi_{i, t} \mid \phi_{i, t+1}, y^{t}, \theta^{T}, \sigma^{T}, \Omega, \Xi, \Psi\right)$.

- Step 4: sample from $p\left(\theta^{T} \mid y^{T}, \sigma^{T}, \phi^{T}, \Omega, \Xi, \Psi, s^{T}\right)$

Conditional on all other parameters and the observables we have

$$
\begin{aligned}
& y_{t}=X_{t}^{\prime} \theta_{t}+\varepsilon_{t} \\
& \theta_{t}=\theta_{t-1}+\omega_{t}
\end{aligned}
$$

Draws for $\theta_{t}$ can be obtained from a $N\left(\theta_{t \mid t+1}, P_{t \mid t+1}\right)$, where $\theta_{t \mid t+1}=E\left(\theta_{t} \mid \theta_{t+1}, y^{T}, \sigma^{T}, \phi^{T}, \Omega, \Xi, \Psi\right)$ and $P_{t \mid t+1}=\operatorname{Var}\left(\theta_{t} \mid \theta_{t+1}, y^{T}, \sigma^{T}, \phi^{T}, \Omega, \Xi, \Psi\right)$ are obtained with the algorithm of Carter and Kohn (1994).

- Step 5: sample from $p\left(\Omega \mid y^{T}, \theta^{T}, \sigma^{T}, \phi^{T}, \Xi, \Psi, s^{T}\right)$

Conditional on the other coefficients and the data, $\Omega$ has an Inverse-Wishart distribution with scale matrix $\Omega_{1}=d f_{\Omega_{0}} \Omega_{0}+\Delta \theta_{t}\left(\Delta \theta_{t}\right)^{\prime}$. To draw a realization for $\Omega$ make $d f_{\Omega_{1}}$ independent draws $z_{i}\left(i=1, \ldots, d f_{\Omega_{1}}\right)$, where $d f_{\Omega_{1}}=d f_{\Omega_{0}}+T$, from $N\left(0, \Omega_{1}^{-1}\right)$ and compute $\Omega=\sum_{i=1}^{d f \Omega_{1}} z_{i}$ (see Gelman et. al., 1995).

- Step 6: sample from $p\left(\Xi_{i, i} \mid y^{T}, \theta^{T}, \sigma^{T}, \phi^{T}, \Omega, \Psi, s^{T}\right)$

Conditional the other coefficients and the data, $\Xi$ has an Inverse-Wishart distribution with scale matrix $\Xi_{1}=d f_{\Xi_{0}} \Xi_{0}+\Delta \log \sigma_{t}\left(\Delta \log \sigma_{t}\right)^{\prime}$. Draws are obtained as in step 5 .

- Step 7: sample from $p\left(\Psi \mid y^{T}, \theta^{T}, \sigma^{T}, \phi^{T}, \Omega, \Xi, s^{T}\right)$.

These volatilities can be drawn separately for each $(i=1, \ldots, \mathrm{n})$. Conditional on the other coefficients and the data, $\Psi_{i}$ has in fact an Inverse-Wishart distribution with scale matrix $\Psi_{i, 1}=d f_{\Psi_{i, 0}} \Psi_{i, 0}+\Delta \phi_{i, t}\left(\Delta \phi_{i, t}\right)^{\prime}$. Draws are obtained as in step 5 . 


\section{References}

Bernanke, B. and I. Mihov (1998), "Measuring Monetary Policy", The Quarterly Journal of Economics, 113:869-902.

Blanchard, O.J. and J. Simon (2000), "The Long and Large Decline in U.S. Output Volatility", Brookings Papers on Economic Activity, 1, 135-147.

Boivin, J., and M. Giannoni (2006), "Has Monetary Policy Become More Effective Powerful?", Review of Economics and Statistics 88(3), 445-462.

Campbell, J. and Z. Herkowitz (2006), "The role of Collateralized Household debt in Macroeconomic Stabilization", Federal Reserve of Chicago, manuscript.

Canova, F. (2005) "What explains the Great Moderation in the US? A structural analysis", forthcoming, Journal of the European Economic Association.

Canova, F. and M. Paustian (2007) "Measurement with some theory: using sign restrictions to evaluate business cycle models", available at www.econ.upf.edu/crei/people/canova.

Canova, F. and L. Sala (2006), "Back to square one: identification in DSGE models", available at www.econ.upf.edu/crei/people/canova.

Cogley, T. and T.J. Sargent (2001), "Evolving Post-World War II U.S. Inflation Dynamics", NBER Macroeconomic Annual, 16,.

Cogley, T. and T.J. Sargent (2005), "Drifts and Volatilities: Monetary Policies and Outcomes in the Post WWII U.S. ", Review of Economic Dynamics, 8, 262-302.

Clarida, R., J. Gali and M. Gertler (2000), "Monetary Policy Rule and Macroeconomic Stability: Evidence and Some Theory", Quarterly Journal of Economics, CXV, 147-180.

Gallant, R., P. Rossi and G. Tauchen (1993), "Non Linear Dynamic Structures", Econometrica, 61, 871-907.

Gambetti, L., E. Pappa, and F. Canova (2005), "The structural Dynamics of US Output and Inflation, what explains the changes", forthcoming Journal of Money Banking and Credit.

Hanson, M. (2006), "Varying Monetary Policy Regimes: a Vector Autoregressive Investigation", Journal of Economic and Business, 58, 407-427.

Kim, S., N. Shepard and S. Chib (1998), "Stochastic Volatility: likelihood inference and comparison with ARCH models", Review of Economic Studies, 65, 361-393.

Koop, G., H. Pesaran and S. Potter (1996), "Impulse Response Analysis in Non-Linear Multivariate Models", Journal of Econometrics, 74, 119-147.

Leeper, E. and T. Zha (2003), "Small Policy Interventions", Journal of Monetary Eco- 
nomics, 50, 1673-1700.

Lubik, T. and F. Schorfheide (2004), "Testing for Indeterminacy: An application to US monetary policy", American Economic Review, 94, 190-217.

McConnell, M. and G. Perez Quiros (2000), "Output fluctuations in the US: what has changed since the early 1980s? ", American Economic Review, 90, 1464-1476.

Orphanides, A. (2004), "Monetary Policy Rules, Macroeconomic Stability, and Inflation: A View from the Trenches", Journal of Money, Banking and Credit, 36, 151-175.

Primiceri, G. (2005), "Time Varying Structural Vector Autoregression and Monetary Policy", Review of Economic Studies, 72, 821-852.

Pivetta, F. and R. Reis (2007), "The Persistence of Inflation in the US", Journal of Economic Dynamics and Control, 31, 1326-1358.

Rubio Ramirez, J. and J. Fernandez Villaverde, (2007), "How Structural are Structural Parameters?" NBER Macroeconomic Annual, 22.

Sargent, T. (1984), "Vector Autoregression, Policy and Advice",American Economic Review, 74, 408-415.

Sargent, T. (1999), The Conquest of American Inflation, Princeton University Press, Princeton, N.J..

Sims, C. (1982), "Policy Analysis with econometric models ", Brookings Papers on Economic Activity, 1, 107-164.

Sims, C. (2001), Comment to "Evolving post WWII US inflation dynamics", NBER Macroeconomic Annual, 16.

Sims, C.A. and T. Zha (2006), "Were there Regime Switches in US Monetary Policy", American Economic Review, 96(1), 54-81.

Schorfheide, F. (2005), "Learning and Monetary Policy Shifts", Review of Economic Dynamics, 8, 392-419.

Stock, J. and M. Watson (2003), " Has Business Cycle Changed and Why?", NBER Macroeconomic Annual, 17, 159-218. 
Figure 1
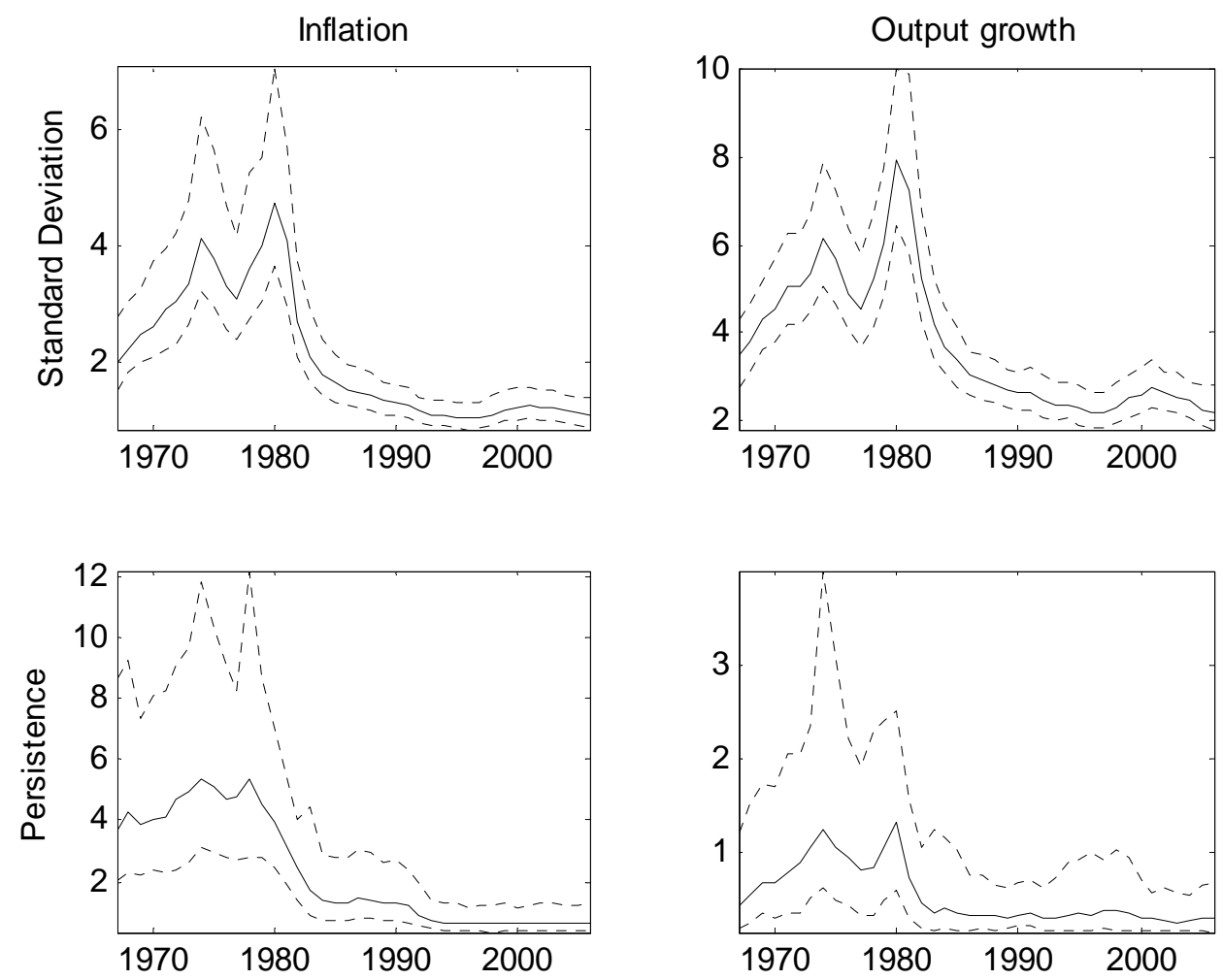

Figure 2a

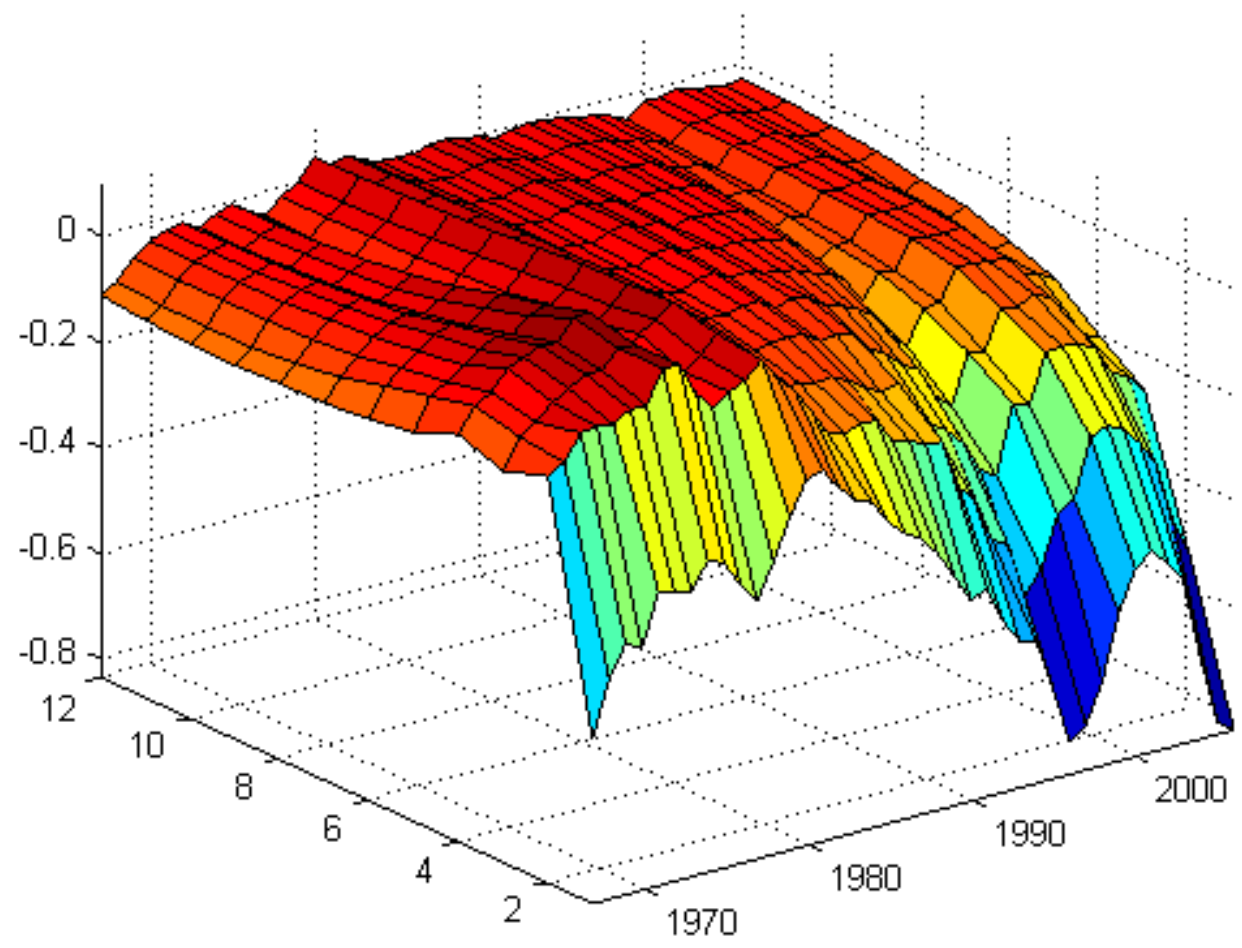


Figure 2b

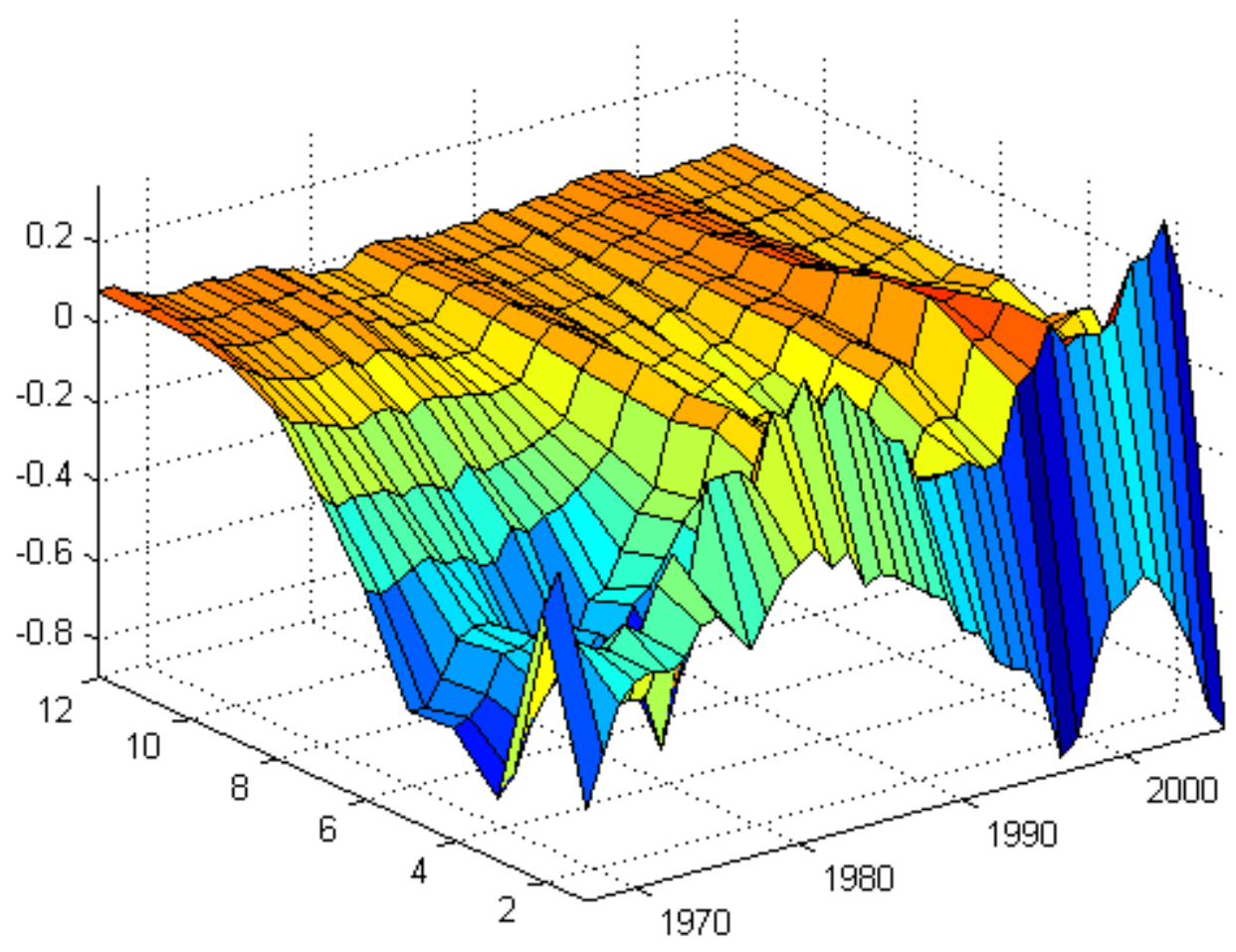

Figure 2c

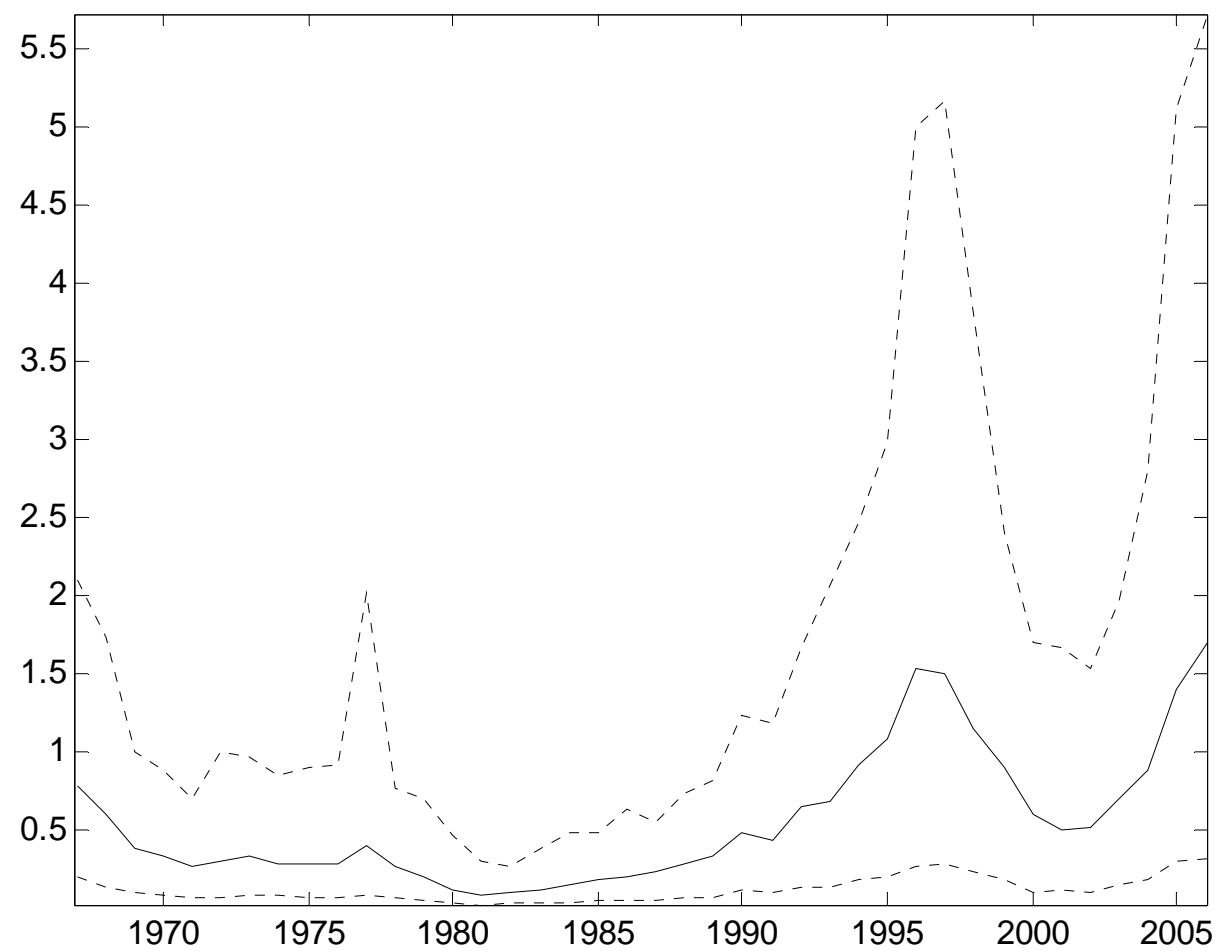


Figure 2d

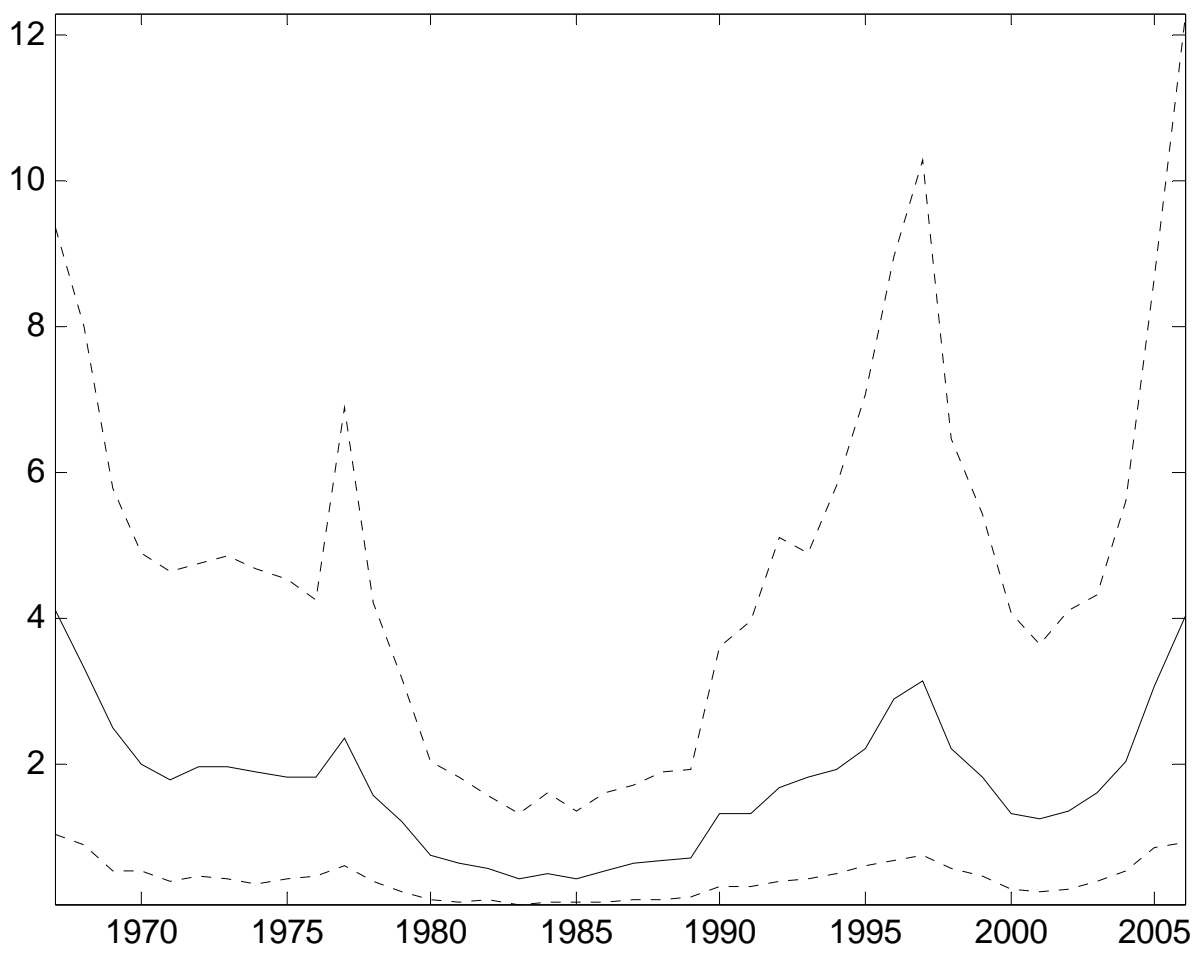

Figure 3

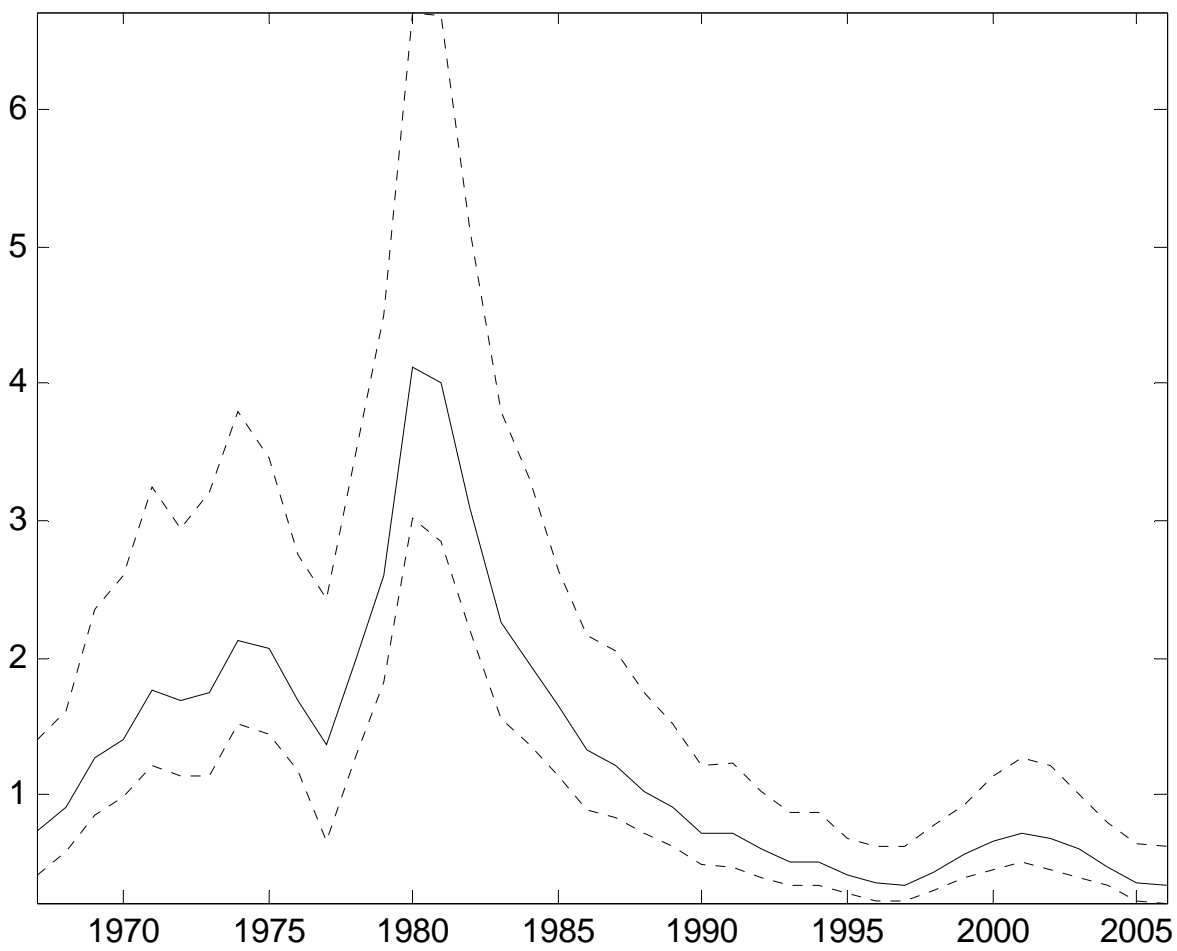


Figure 4
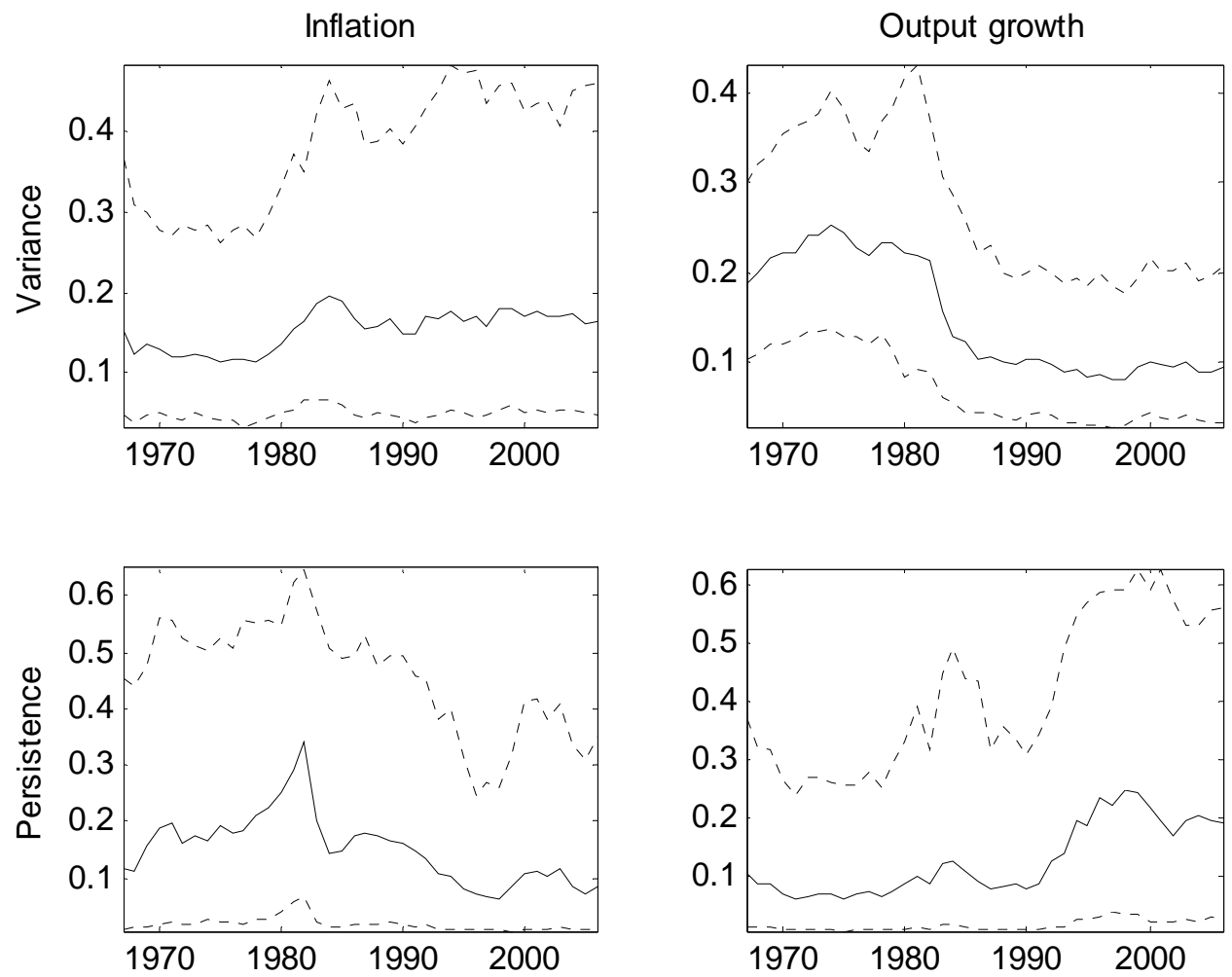
Figure 5

Inflation

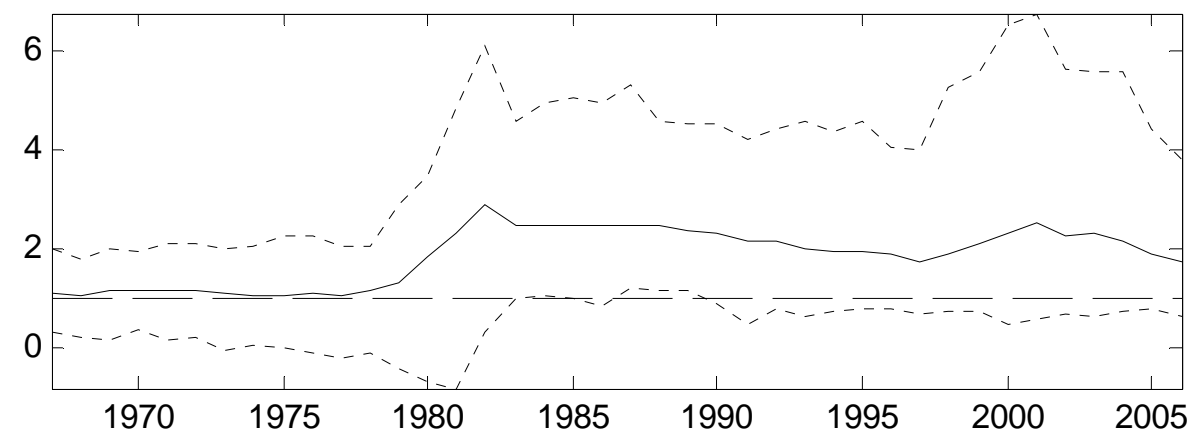

Output growth

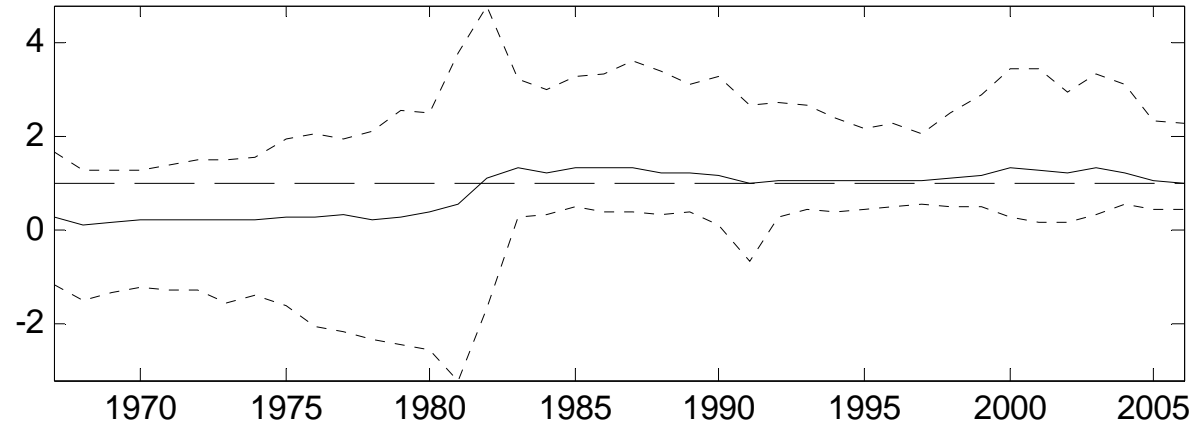

Money

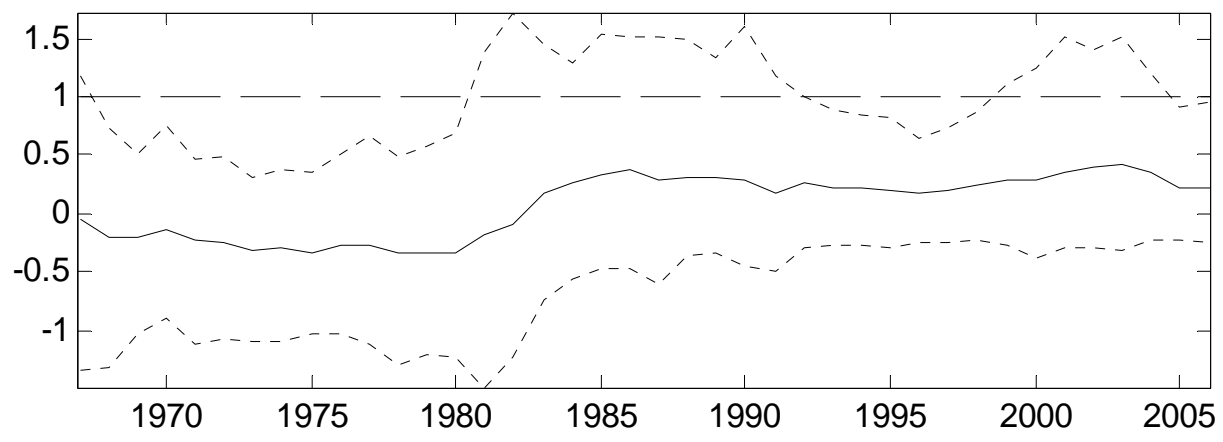


Figure 6a

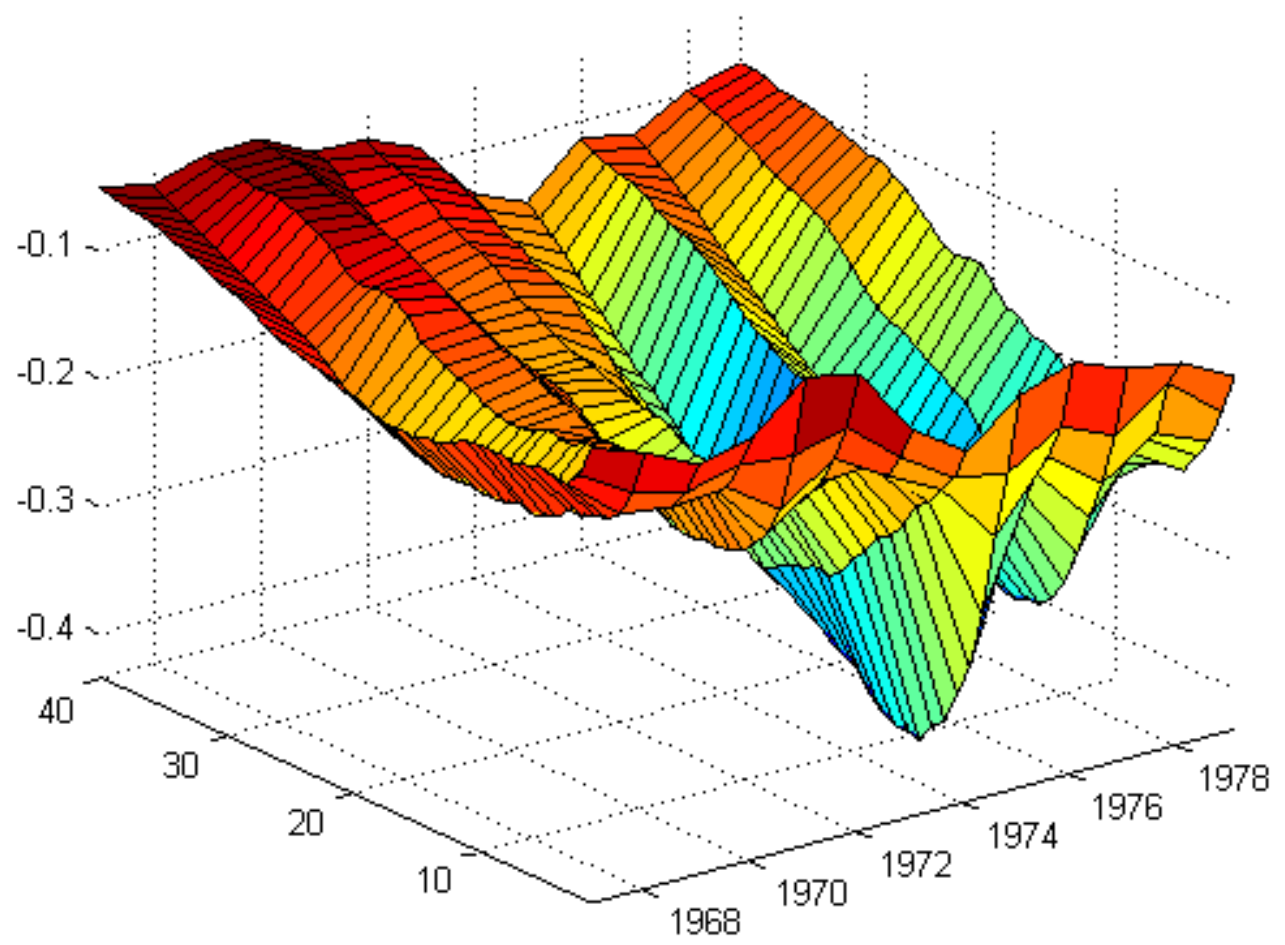

Figure 6b

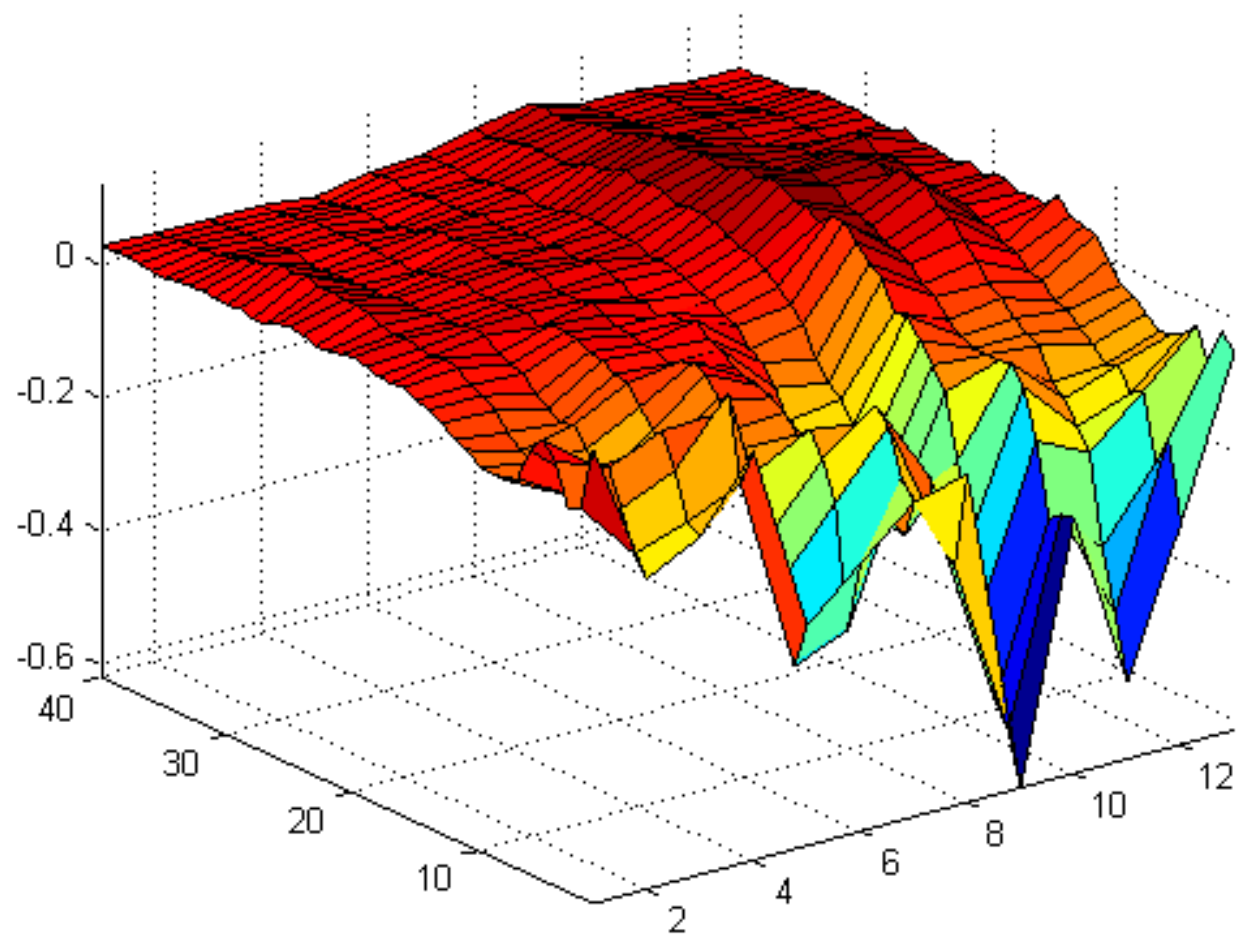


Figure 7

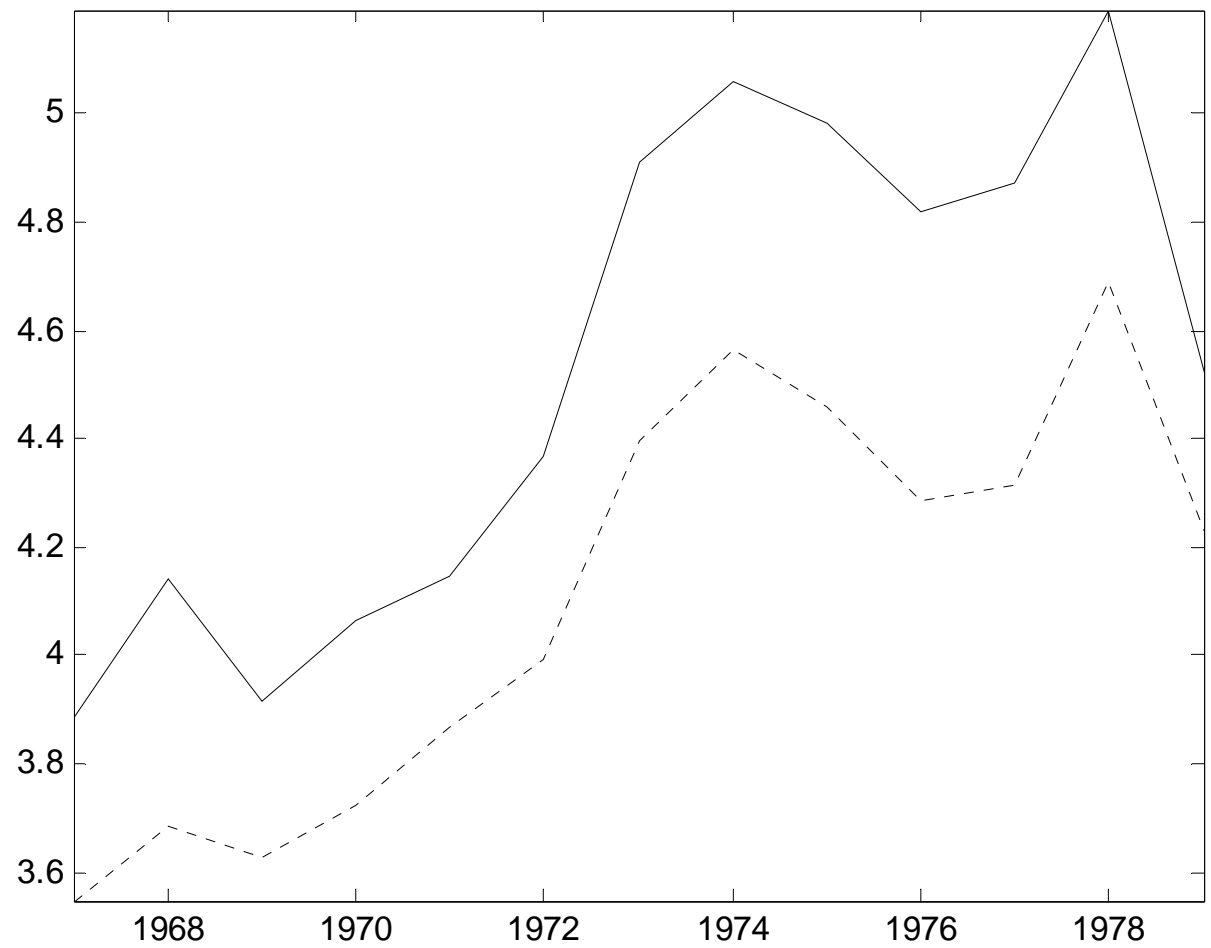

